\title{
APOB codon 4311 polymorphism is associated with hepatitis $C$ virus infection through altered lipid metabolism
}

\author{
Rie Harada', Masako Kimura', Yasushi Sato', Tatsuya Taniguchi', Tetsu Tomonari', Takahiro Tanaka', \\ Hironori Tanaka', Naoki Muguruma', Hirohiko Shinomiya², Hirohito Honda ${ }^{3}$, Issei Imoto ${ }^{4}$, Masahiro Sogabe ${ }^{5}$, \\ Toshiya Okahisa ${ }^{5}$ and Tetsuji Takayama ${ }^{*}$
}

\begin{abstract}
Background: It has been reported that some single-nucleotide polymorphisms (SNPs) in lipid regulators such as apolipoproteins and cell surface molecules for hepatitis $\mathrm{C}$ virus (HCV) entry into hepatocytes are associated with HCV infection. However, it is unknown how HCV infection is affected by altered lipid metabolism resulting from the SNPs. We investigated the relationship between these SNPs and HCV infection status, and also analyzed the mechanism by which these SNPs mediate HCV infection via lipid metabolism alterations.
\end{abstract}

Methods: Serum lipid and apolipoprotein profiles were tested in $158 \mathrm{HCV}$-positive and $220 \mathrm{HCV}$-negative subjects. We selected 22 SNPs in five lipid regulator genes which were related to HCV entry into hepatocytes and to lipid metabolism (APOA1, APOB, SR-B1, LDLR, and $A P O E)$, and their polymorphisms were analyzed using the PCR-sequencespecific oligonucleotide probe-Luminex method.

Results: An APOB N4311S (g.41553a > g) SNP, rs1042034, was significantly associated with HCV positivity; the HCV positivity rate for the minor allele AA genotype was significantly higher than for genotype AG $+G G(P=0.016)$. Other SNPs except for APOB P2712L SNP rs676210, which is in linkage disequilibrium with rs1042034, showed no significant difference in genotype distribution. The serum level of low density lipoprotein-cholesterol (LDL-C) in the genotype AA group was significantly lower than in the genotype non-AA group $(P=0.032)$, whereas the triglyceride (TG) level was significantly higher $(P=0.007)$.

Conclusion: An APOB SNP, rs 1042034, is closely associated with HCV infection through lipid metabolism alteration. The minor allele AA genotype might contribute to facilitating serum LDL uptake into hepatocytes via LDLR by modifying their affinity and interaction and may have an influence on HCV infection by their entry to the liver through the LDLR.

Keywords: Hepatitis C virus, Lipid metabolism, SNPs, ApoB

\section{Background}

Hepatitis $\mathrm{C}$ virus (HCV) infects approximately 185 million people worldwide [1]. HCV infection typically causes chronic liver disease and can lead to liver cirrhosis and hepatocellular carcinoma (HCC) [2]. Accumulating studies have revealed that the HCV life cycle is closely associated with host lipid metabolism.

\footnotetext{
* Correspondence: takayama@tokushima-u.ac.jp

${ }^{1}$ Department of Gastroenterology and Oncology, Tokushima University

Graduate School of Biomedical Sciences, 3-18-15, Kuramoto-cho, Tokushima

770-8503, Japan

Full list of author information is available at the end of the article
}

It has been reported that HCV entry into hepatocytes occurs through cell surface molecules such as low density lipoprotein receptor (LDLR), scavenger receptor class B type 1 (SR-B1), claudin-1 (CLDN1), DC-SIGN, L-SIGN, and CD81. However, the details of the underlying mechanisms have not yet been clarified [3]. Among these molecules LDLR and SR-B1 also play a crucial role in lipid metabolism. Apolipoproteins are proteins on the surface of lipoprotein particles and stabilize the structure of lipoproteins. Apolipoprotein B (APOB) is one of the major apolipoproteins and it transfers lipoproteins such as chylomicron, very low density lipoprotein (VLDL), 
and low density lipoprotein (LDL) as a carrier. It is secreted from the liver as a component of the outer surface of VLDL particles, which are also produced in the liver, and circulates in blood, irreversibly associating with VLDL and LDL. APOB-100 serves as a ligand for LDLRs on the cell membrane of hepatocytes. Thus, the LDL particle enters into hepatocyte through the LDLR [4-6].

In the $\mathrm{HCV}$ life cycle, $\mathrm{HCV}$ replication begins in a membranous web on the endoplasmic reticulum membrane in hepatocytes, where VLDL assembly also occurs. Both HCV particles and VLDL particles are secreted from hepatocytes and circulate in blood as a complex referred to as a lipo-viral particle (LVP). Furthermore, APOB-100 and apolipoprotein E (APOE), which are referred to as VLDL-associated proteins, are present on the surface of the complex. They form LVP with $\mathrm{HCV}$ particles, indicating that they are deeply involved in the formation of infectious $\mathrm{HCV}$ particles [7]. After circulation in the blood, infectious HCV particles enter into hepatocytes with LDL through the LDLR [8].

It is well known that apolipoproteins and cell surface molecules such as LDLR and SR-B1 have singlenucleotide polymorphisms (SNPs), and some of the SNPs cause lipid metabolism disorders, leading to a high risk of cardiovascular events [9-11]. Regarding the association with $\mathrm{HCV}$, several studies have suggested that SNPs of these lipid-metabolic regulators correlate with HCV infection; e.g., an SNP in LDLR exon 13 (rs5925) is associated with susceptibility to HCV infection [12]; an SNP in $L D L R$ exon8 (rs11669576) is associated with severity of hepatic fibrosis; and an SNP in $L D L R$ exon10 (rs5930) is associated with viral clearance and overall inflammation of the liver [13]. SNPs in LDLR 3'UTR region (rs1433099) and intron 14 (rs2569540) have been reported to have an association with hepatitis $\mathrm{C}$ viral load in the pre-treatment state [14]. Furthermore, polymorphisms of $A P O E$ have been reported to be associated with persistent $\mathrm{HCV}$ infection and the degree of liver damage $[15,16]$.

Thus, it is assumed that SNPs of lipid regulators have a strict association with HCV infection and lipid metabolism disorders. However, the relationship between $\mathrm{HCV}$ infection and lipid metabolism disorder among the SNPs of these lipid regulators have not yet been fully elucidated. Therefore, in this study, we first investigated the relationship between the SNPs of lipid regulator genes such as apolipoproteins and cell surface molecules that affect the HCV life cycle, and HCV infection status comparing $\mathrm{HCV}$-positive and $\mathrm{HCV}$-negative subjects. We then examined differences in lipid metabolism between each SNP genotype and analyzed the causal relationship between the SNP and $\mathrm{HCV}$ infection status through altered lipid metabolism.

\section{Methods}

\section{Subjects}

This study included a total of 378 subjects who visited our university hospital and affiliated hospitals from November 2010 to March 2014. All subjects were Japanese and were between 41 and 76 years old. Patients who had received prior or ongoing anti-viral therapy and treatment for lipid metabolism disorders were excluded. We also excluded patients with inherited lipid metabolism disorders such as familial hypercholesterolemia and secondary lipid metabolism disorders such as hypothyroidism and kidney diseases.

An HCV antibody test was carried out for all subjects; 158 were $\mathrm{HCV}$ positive and HCV RNA detectable by RT-PCR, and 220 were HCV negative. Serum HCV RNA levels were measured using COBAS TaqMan HCV Auto Assay System (Roche Diagnostics, Tokyo, Japan; lower limit of quantification, $1.2 \mathrm{log} \mathrm{IU} / \mathrm{ml})$. HCV genotypes were determined by direct sequence method at BML, Inc. (Saitama, Japan). Serum transaminase, total bilirubin, albumin levels, and prothrombin time were measured, and ultrasonography or contrast-enhanced computed tomography was performed to check liver function and search for HCC. Based on these results, subjects with severe liver dysfunction of Child-Pugh class $\mathrm{B}$ and $\mathrm{C}$ were excluded from the study. Patients with conditions associated with liver dysfunction such as HCC, hepatitis B virus (HBV) infection, or nonalcoholic steatohepatitis (NASH) were also excluded from the study. The study protocol was approved by the institutional review board of each hospital and all patients provided written informed consent to participate in this study.

\section{Measurement of serum lipids and apolipoproteins}

Serum lipids and apolipoproteins were tested after fasting overnight for 10 to $12 \mathrm{~h}$. We measured low density lipoprotein-cholesterol (LDL-C), high density lipoproteincholesterol (HDL-C), and triglyceride (TG) according to standard procedures at our university hospital and affiliated hospitals. Serum levels of apolipoproteins (apolipoprotein A1 [APOA1], apolipoprotein A2 [APOA2], APOB, apolipoprotein $\mathrm{C} 2$ [APOC2], apolipoprotein $\mathrm{C} 3$ [APOC3], and APOE) were measured by immune nephelometry at SRL, Inc. (Tokyo, Japan).

\section{SNP selection}

We selected 22 SNPs in five genes (APOA1, $A P O B$, $S R-B 1, L D L R$, and $A P O E$ ) which are related to $\mathrm{HCV}$ entry into hepatocytes and are associated with lipid metabolism disorders according to previous studies; three SNPs (rs613808, rs2727784, and rs11216158) in APOA1 [17], five SNPs (rs676210, rs1042031, rs693, rs1801701, and rs1042034) in $A P O B$ [9], three SNPs (rs4238001, rs61932577, and rs5888) in SR-B1 [10], nine SNPs 
(rs17249134, rs17249141, rs2228671, rs11669576, rs5930, rs688, rs5925, rs2569542, and rs14158) in $L D L R$ [13], and two SNPs (rs429358 and rs7412) in APOE [18].

\section{Genotyping}

Genomic DNA was extracted from peripheral blood using the phenol-chloroform method and stored at $-4{ }^{\circ} \mathrm{C}$. Genotypes of all SNPs selected in this study were analyzed at G\&G Science Co., Ltd. (Fukushima, Japan) using the PCR-sequence-specific oligonucleotide probe-Luminex method, as described previously [19].

\section{Statistical analysis}

Student's $t$-test was used to compare serum lipid and apolipoprotein levels between the two subject groups (HCV-positive and HCV-negative) as well as the genotype groups for each SNP. The genotype distributions for each SNP were analyzed using $\chi^{2}$ test. A $P$ value of less than 0.05 was considered statistically significant. The statistical analyses were performed using Statcel 4 (OMS Ltd., Saitama, Japan). Linkage disequilibrium was analyzed using the program Haploview from the Broad Institute website (https://www.broadinstitute.org/haploview/haploview).

\section{Results}

\section{Characteristics of the subjects}

The study included 158 patients with HCV infection and 220 subjects without HCV infection. The age and sex ratio were well balanced between the groups. There was no significant difference in serum total bilirubin, AST, ALT and albumin levels, and prothrombin values (\%), which are indicative of hepatic functional reserve, and were also well balanced between groups. HCV infected patients were genotype $1 \mathrm{~b}(n=128), 2 \mathrm{a}(n=5), 2 \mathrm{~b}(n=9), 3 \mathrm{a}(n=1)$, and undetermined $(n=6)$. The remaining nine patients received only serotype analysis: serotype I $(n=7)$ and serotype II $(n=2)$.

Among 158 subjects with HCV infection, the estimated median duration of $\mathrm{HCV}$ infection was 51 (IQR 44.3-55.0) years, and the median HCV RNA concentration in $\mathrm{HCV}$-infected patients was 6.5 (IQR 6.0-6.9) $\log \mathrm{IU} / \mathrm{ml}$.

\section{Profile of serum lipids and apolipoproteins in HCV-positive and HCV-negative subjects}

Since HCV infection reportedly causes a change in serum lipid levels, we first compared the serum lipid levels between $158 \mathrm{HCV}$-positive subjects and 220 HCV-negative subjects (Table 1). The serum levels of total cholesterol (TC), LDL-C, and HDL-C in HCV-positive subjects were significantly lower than in $\mathrm{HCV}$ negative subjects, whereas the serum TG level in HCVpositive subjects was higher than in $\mathrm{HCV}$-negative
Table 1 Profile of serum lipids and apolipoproteins in HCV-positive and HCV-negative subjects

\begin{tabular}{llllll}
\hline & & Normal range & HCV + & HCV- & $P$-value \\
\hline TC & $(\mathrm{mg} / \mathrm{dl})$ & $120.0-219.0$ & $169.4 \pm 31.3$ & $207.2 \pm 32.0$ & $<0.001$ \\
LDL-C & $(\mathrm{mg} / \mathrm{dl})$ & $65.0-139.0$ & $96.8 \pm 24.3$ & $124.8 \pm 29.5$ & $<0.001$ \\
HDL-C & $(\mathrm{mg} / \mathrm{dl})$ & $40.0-90.0$ & $53.1 \pm 18.5$ & $62.9 \pm 17.6$ & $<0.001$ \\
TG & $(\mathrm{mg} / \mathrm{dl})$ & $30.0-149.0$ & $106.6 \pm 52.2$ & $98.3 \pm 56.6$ & 0.173 \\
APOA1 & $(\mathrm{mg} / \mathrm{dl})$ & $120.0-160.0$ & $139.6 \pm 31.3$ & $155.2 \pm 29.2$ & $<0.001$ \\
APOA2 & $(\mathrm{mg} / \mathrm{dl})$ & $25.0-34.6$ & $29.6 \pm 5.5$ & $30.8 \pm 4.9$ & 0.022 \\
APOB & $(\mathrm{mg} / \mathrm{dl})$ & $70.0-106.0$ & $77.2 \pm 17.9$ & $96.7 \pm 22.8$ & $<0.001$ \\
APOC2 & $(\mathrm{mg} / \mathrm{dl})$ & $1.6-4.2$ & $2.1 \pm 1.0$ & $4.0 \pm 1.7$ & $<0.001$ \\
APOC3 & $(\mathrm{mg} / \mathrm{dl})$ & $5.6-9.5$ & $6.0 \pm 2.3$ & $9.2 \pm 3.1$ & $<0.001$ \\
APOE & $(\mathrm{mg} / \mathrm{dl})$ & $2.7-4.5$ & $4.4 \pm 1.1$ & $4.7 \pm 1.2$ & 0.011 \\
\hline
\end{tabular}

Data represent mean and standard deviation values and $P$-values were calculated using Student's t-test

subjects, although the difference was not statistically significant. Moreover, serum levels of all six apolipoproteins (APOA1, APOA2, APOB, APOC2, APOC3, and $\mathrm{APOE}$ ) in $\mathrm{HCV}$-positive subjects were significantly lower than in HCV-negative subjects. These results were fairly consistent with previous reports $[6,20,21]$.

\section{Association of SNP genotype with HCV infection}

To examine the relationship between SNP genotype in lipid regulator genes and $\mathrm{HCV}$ infection status, we analyzed the genotype distribution of the selected 22 SNPs in APOA1, APOB, SR-B1, LDLR, and APOE, and compared them between HCV-positive and HCVnegative groups (Table 2). Of the 22 SNPs examined, five were monomorphic in our study population; rs1801701 in $A P O B$; rs61932577 in $S R-B 1$; rs17249134, rs17249141, and rs11669576 in $L D L R$.

In the comparison of overall genotype distributions for each SNP, an $A P O B$ N4311S (g.41553a >g) SNP, rs1042034, showed a marginally non-significant trend with respect to $\mathrm{HCV}$ positivity $\left(P=0.051, X^{2}=5.963\right)$; the frequency of the $\mathrm{A}$ allele in $\mathrm{HCV}$-positive subjects was higher than in $\mathrm{HCV}$-negative subjects. In the comparison of specific genotypes (GG + AG vs. AA), the $\mathrm{HCV}$ positivity rate in the genotype AA group was significantly higher than in the genotype GG + AG group $\left(P=0.016, X^{2}=5.828\right)$. These results suggest that minor allele homozygosity (genotype AA) in rs1042034 might be associated with $\mathrm{HCV}$ infection. Moreover, an $A P O B$ P2712L (g.35310c >t) SNP, rs676210, showed a similar tendency to that of rs1042034; i.e., the frequency of the genotype CC allele in rs676210 was significantly higher than that of genotype TT $+\mathrm{CT}$ in $\mathrm{HCV}$-positive subjects $\left(P=0.031, \chi^{2}=4.673\right)$. Other SNPs aside from these two showed no significant difference in genotype distribution between $\mathrm{HCV}$-positive and $\mathrm{HCV}$-negative subjects. 
Table 2 Association of SNP genotype with HCV infection

\begin{tabular}{|c|c|c|c|c|c|c|c|c|c|}
\hline \multirow[b]{2}{*}{ APOA1 } & \multirow[b]{2}{*}{ rs613808 } & \multirow{2}{*}{$\begin{array}{l}\text { Alleles } \\
\text { G/A }\end{array}$} & \multirow[t]{2}{*}{$\mathrm{HCV}$} & \multicolumn{3}{|c|}{$\begin{array}{l}\text { Overall genotype } \\
\text { distribution(n) }\end{array}$} & \multirow[t]{2}{*}{$\begin{array}{l}P \text {-value } \\
\text { (x2 value) }\end{array}$} & \multirow[t]{2}{*}{$\begin{array}{l}\text { Comparison of } \\
\text { specific genotypes }\end{array}$} & \multirow[t]{2}{*}{$\begin{array}{l}P \text {-value } \\
\text { (x2 value) }\end{array}$} \\
\hline & & & & $\mathrm{AA}$ & GA & GG & & & \\
\hline & & & + & 72 & 74 & 12 & 0.192 & & \\
\hline & & & - & 120 & 83 & 17 & $(3.297)$ & & \\
\hline & rs2727784 & $\mathrm{G} / \mathrm{A}$ & & GG & GA & AA & & & \\
\hline & & & + & 75 & 71 & 12 & 0.290 & & \\
\hline & & & - & 122 & 82 & 16 & $(2.473)$ & & \\
\hline & rs11216158 & $A / G$ & & GG & $A G$ & $\mathrm{AA}$ & & & \\
\hline & & & + & 99 & 56 & 3 & 0.231 & & \\
\hline & & & - & 150 & 62 & 8 & $(2.933)$ & & \\
\hline \multirow[t]{15}{*}{ APOB } & rs676210 & $C / T$ & & $\pi$ & $\mathrm{CT}$ & $\mathrm{CC}$ & & & \\
\hline & & & + & 88 & 57 & 13 & 0.091 & $\Pi+C T$ vs $C C$ & 0.031 \\
\hline & & & - & 133 & 80 & 7 & $(4.784)$ & & $(4.673)$ \\
\hline & rs1042031 & $\mathrm{G} / \mathrm{A}$ & & GG & GA & $\mathrm{AA}$ & & & \\
\hline & & & + & 150 & 8 & 0 & & & \\
\hline & & & - & 205 & 15 & 0 & & & \\
\hline & rs693 & $C / T$ & & $C C$ & $\mathrm{CT}$ & $\pi$ & & & \\
\hline & & & + & 147 & 11 & 0 & & & \\
\hline & & & - & 199 & 21 & 0 & & & \\
\hline & rs1801701 & $\mathrm{G} / \mathrm{A}$ & & GG & GA & AA & & & \\
\hline & & & + & 158 & 0 & 0 & & & \\
\hline & & & - & 220 & 0 & 0 & & & \\
\hline & rs1042034 & $A / G$ & & GG & $A G$ & AA & & & \\
\hline & & & + & 88 & 57 & 13 & 0.051 & $\mathrm{GG}+\mathrm{AG}$ vs $\mathrm{AA}$ & 0.016 \\
\hline & & & - & 134 & 80 & 6 & $(5.963)$ & & (5.828) \\
\hline \multirow[t]{9}{*}{ SR-B1 } & rs4238001 & $\mathrm{G} / \mathrm{A}$ & & GG & GA & AA & & & \\
\hline & & & + & 157 & 1 & 0 & & & \\
\hline & & & - & 220 & 0 & 0 & & & \\
\hline & rs61932577 & $C / T$ & & $C C$ & $\mathrm{CT}$ & $\pi$ & & & \\
\hline & & & + & 158 & 0 & 0 & & & \\
\hline & & & - & 220 & 0 & 0 & & & \\
\hline & rs5888 & $C / T$ & & $\mathrm{CC}$ & $\mathrm{CT}$ & $\pi$ & & & \\
\hline & & & + & 96 & 54 & 10 & 0.761 & & \\
\hline & & & - & 128 & 82 & 10 & $(0.546)$ & & \\
\hline \multirow[t]{9}{*}{ LDLR } & rs17249134 & $\mathrm{T} / \mathrm{G}$ & & GG & $\mathrm{TG}$ & $\pi$ & & & \\
\hline & & & + & 158 & 0 & 0 & & & \\
\hline & & & - & 220 & 0 & 0 & & & \\
\hline & rs17249141 & $\mathrm{T} / \mathrm{C}$ & & CC & $\mathrm{TC}$ & $\pi$ & & & \\
\hline & & & + & 158 & 0 & 0 & & & \\
\hline & & & - & 220 & 0 & 0 & & & \\
\hline & rs2228671 & $C / T$ & & $C C$ & $\mathrm{CT}$ & $\pi$ & & & \\
\hline & & & + & 156 & 2 & 0 & & & \\
\hline & & & - & 219 & 1 & 0 & & & \\
\hline
\end{tabular}


Table 2 Association of SNP genotype with HCV infection (Continued)

\begin{tabular}{|c|c|c|c|c|c|c|c|c|c|}
\hline & & Alleles & $\mathrm{HCV}$ & $\begin{array}{l}\text { Over } \\
\text { distril }\end{array}$ & $\begin{array}{l}\text { otype } \\
\text { (n) }\end{array}$ & & $\begin{array}{l}P \text {-value } \\
\text { (x2 value) }\end{array}$ & $\begin{array}{l}\text { Comparison of } \\
\text { specific genotypes }\end{array}$ & $\begin{array}{l}P \text {-value } \\
\text { (x2 value) }\end{array}$ \\
\hline & rs11669576 & $A / G$ & & GG & $A G$ & $\mathrm{AA}$ & & & \\
\hline & & & + & 158 & 0 & 0 & & & \\
\hline & & & - & 220 & 0 & 0 & & & \\
\hline & rs5930 & $\mathrm{G} / \mathrm{A}$ & & GG & GA & AA & & & \\
\hline & & & + & 66 & 73 & 19 & 0.957 & & \\
\hline & & & - & 89 & 105 & 26 & $(0.088)$ & & \\
\hline & rs688 & $\mathrm{T} / \mathrm{C}$ & & CC & TC & $\pi$ & & & \\
\hline & & & + & 120 & 36 & 2 & 0.664 & & \\
\hline & & & - & 160 & 55 & 5 & $(0.820)$ & & \\
\hline & rs5925 & $C / T$ & & $\pi$ & $\mathrm{CT}$ & $\mathrm{CC}$ & & & \\
\hline & & & + & 114 & 42 & 2 & 0.479 & & \\
\hline & & & - & 149 & 65 & 6 & $(1.472)$ & & \\
\hline & rs2569542 & $A / G$ & & GG & $A G$ & $\mathrm{AA}$ & & & \\
\hline & & & + & 138 & 19 & 1 & 0.935 & & \\
\hline & & & - & 190 & 28 & 2 & $(0.135)$ & & \\
\hline & rs14158 & $\mathrm{G} / \mathrm{A}$ & & GG & GA & $\mathrm{AA}$ & & & \\
\hline & & & + & 58 & 75 & 25 & 0.928 & & \\
\hline & & & - & 84 & 100 & 36 & $(0.150)$ & & \\
\hline APOE & rs429358 & $\mathrm{T} / \mathrm{C}$ & & $\pi$ & TC & CC & & & \\
\hline & & & + & 131 & 27 & 0 & 0.564 & & \\
\hline & & & - & 177 & 41 & 2 & $(0.333)$ & & \\
\hline & rs7412 & $C / T$ & & $\mathrm{CC}$ & $\mathrm{CT}$ & $\pi$ & & & \\
\hline & & & + & 142 & 16 & 0 & & & \\
\hline & & & - & 196 & 24 & 0 & & & \\
\hline
\end{tabular}

The rs1042034 SNP is located at the $A P O B$ carboxylterminal site, 6243 nucleotides away from rs676210, and this is reportedly in strong linkage disequilibrium [9]. The degree of linkage disequilibrium between these SNPs in our study population was also strong $\left(\mathrm{D}^{\prime}=1, r^{2}=0.98\right)$. Therefore, we confined the following association analysis of these SNPs with serum lipids only to rs1042034.

\section{Association of serum lipid and apolipoprotein levels with the rs1042034 genotype}

Since APOB is reported to be associated with serum lipid levels [9], we compared the serum lipid levels between genotypes $\mathrm{AA}$ and non-AA $(\mathrm{GG}+\mathrm{AG})$ in rs1042034 (Table 3). The serum LDL-C level in the genotype AA group was significantly lower than that in the genotype non-AA group $(98.7 \pm 39.4$ vs. $115.1 \pm 30.1$, $P=0.032$ ), whereas the TG level was significantly higher in the genotype AA group than in the genotype non-AA group $(137.7 \pm 67.7$ vs. $100.7 \pm 55.3, P=0.007)$. There were no significant differences in serum levels of APOA1, APOA2, APOB, APOC2, APOC3, and APOE.
Table 3 Association of serum lipid and apolipoprotein levels with the rs1042034 genotype

\begin{tabular}{|c|c|c|c|c|}
\hline & & \multicolumn{2}{|c|}{ Genotype of rs1042034 } & \multirow[t]{2}{*}{$P$-value } \\
\hline & & $\overline{A A}(n)$ & $\mathrm{GG}+\mathrm{AG}(\mathrm{n})$ & \\
\hline TC & $(\mathrm{mg} / \mathrm{dl})$ & $176.7 \pm 46.5(17)$ & $191.8 \pm 36.2(332)$ & 0.100 \\
\hline LDL-C & $(\mathrm{mg} / \mathrm{dl})$ & $98.7 \pm 39.4(17)$ & $115.1 \pm 30.1(316)$ & 0.032 \\
\hline $\mathrm{HDL}-\mathrm{C}$ & $(\mathrm{mg} / \mathrm{dl})$ & $50.8 \pm 19.4(15)$ & $59.6 \pm 18.4(302)$ & 0.074 \\
\hline TG & $(\mathrm{mg} / \mathrm{dl})$ & $137.7 \pm 67.7(18)$ & $100.7 \pm 55.3(321)$ & 0.007 \\
\hline APOA 1 & $(\mathrm{mg} / \mathrm{dl})$ & $137.5 \pm 34.1(19)$ & $149.3 \pm 30.9(355)$ & 0.105 \\
\hline APOA2 & $(\mathrm{mg} / \mathrm{dl})$ & $29.6 \pm 4.9(19)$ & $30.4 \pm 5.2(355)$ & 0.547 \\
\hline APOB & $(\mathrm{mg} / \mathrm{dl})$ & $83.6 \pm 29.5(19)$ & $88.9 \pm 22.6(355)$ & 0.335 \\
\hline APOC2 & $(\mathrm{mg} / \mathrm{dl})$ & $3.2 \pm 1.9(19)$ & $3.2 \pm 1.7(355)$ & 0.945 \\
\hline APOC3 & $(\mathrm{mg} / \mathrm{dl})$ & $7.9 \pm 3.6(19)$ & $7.9 \pm 3.2(355)$ & 0.975 \\
\hline APOE & $(\mathrm{mg} / \mathrm{dl})$ & $4.8 \pm 1.9$ (19) & $4.5 \pm 1.1(355)$ & 0.390 \\
\hline
\end{tabular}


To assess the effect of HCV status on lipid levels, we compared serum lipid and apolipoprotein levels between AA and non-AA genotypes of rs1042034 in HCV-positive and HCV-negative subjects (Table 4). No significant differences were observed in the levels of apolipoproteins between the AA and non-AA groups regardless of $\mathrm{HCV}$ status.

\section{Discussion}

In this study, we demonstrated that the AA genotype of rs1042034 in the APOB gene is significantly related to $\mathrm{HCV}$ infection status and might be associated with the regulation of serum LDL-C and TG levels. These results could suggest a close association between $\mathrm{HCV}$ infection status and lipid metabolism alterations due to the APOB SNP.

$\mathrm{HCV}$ exists in blood as an LVP, with which APOB and APOE are also combined [22]. HCV in LVPs can enter into hepatocytes through LDLRs on the cell membrane [23]. APOB-100 is deeply involved in these steps as a ligand for the LDLR; however, the underlying mechanisms have not yet been clarified in detail [24].

Table 4 Associations of serum lipid and apolipoprotein levels with rs1042034 genotype in HCV-positive and HCV-negative subjects

\begin{tabular}{|c|c|c|c|c|c|}
\hline & & \multirow[t]{2}{*}{$\mathrm{HCV}$} & \multicolumn{2}{|c|}{ Genotype of rs1042034 } & \multirow[t]{2}{*}{$P$-value } \\
\hline & & & $\overline{A A}(n)$ & $G G+A G(n)$ & \\
\hline \multirow[t]{2}{*}{$\overline{\mathrm{TC}}$} & $(\mathrm{mg} / \mathrm{dl})$ & + & $160.9 \pm 43.5(11)$ & $170.3 \pm 30.1(138)$ & 0.342 \\
\hline & & - & $205.7 \pm 39.7(6)$ & $207.1 \pm 32.0(194)$ & 0.917 \\
\hline \multirow[t]{2}{*}{ LDL-C } & $(\mathrm{mg} / \mathrm{dl})$ & + & $86.2 \pm 31.9(11)$ & $97.7 \pm 23.2(114)$ & 0.134 \\
\hline & & - & $121.5 \pm 44.4(6)$ & $124.9 \pm 29.1(202)$ & 0.779 \\
\hline \multirow[t]{2}{*}{$\mathrm{HDL}-\mathrm{C}$} & $(\mathrm{mg} / \mathrm{dl})$ & + & $47.1 \pm 22.6(9)$ & $53.6 \pm 18.2(110)$ & 0.313 \\
\hline & & - & $56.5 \pm 13.1(6)$ & $63.1 \pm 17.7(192)$ & 0.370 \\
\hline \multirow[t]{2}{*}{ TG } & $(\mathrm{mg} / \mathrm{dl})$ & + & $135.3 \pm 66.1(12)$ & $106.3 \pm 54.8(127)$ & 0.088 \\
\hline & & - & $142.5 \pm 31.5(6)$ & $97.0 \pm 55.4(194)$ & 0.052 \\
\hline \multirow[t]{2}{*}{ APOA1 } & $(\mathrm{mg} / \mathrm{dl})$ & + & $130.6 \pm 35.8(13)$ & $140.5 \pm 31.1(144)$ & 0.278 \\
\hline & & - & $152.3 \pm 27.0(6)$ & $155.3 \pm 29.3(211)$ & 0.805 \\
\hline \multirow[t]{2}{*}{ APOA2 } & $(\mathrm{mg} / \mathrm{dl})$ & + & $29.9 \pm 5.6(13)$ & $29.6 \pm 5.5(144)$ & 0.868 \\
\hline & & - & $29.1 \pm 3.5(6)$ & $30.9 \pm 4.9(211)$ & 0.374 \\
\hline \multirow[t]{2}{*}{$A P O B$} & $(\mathrm{mg} / \mathrm{dl})$ & + & $74.1 \pm 21.8(13)$ & $77.7 \pm 17.6(144)$ & 0.490 \\
\hline & & - & $104.3 \pm 35.3(6)$ & $96.5 \pm 22.4(211)$ & 0.407 \\
\hline \multirow[t]{2}{*}{ APOC2 } & $(\mathrm{mg} / \mathrm{dl})$ & + & $2.6 \pm 1.3(13)$ & $2.1 \pm 1.0(144)$ & 0.056 \\
\hline & & - & $4.5 \pm 2.6(6)$ & $4.0 \pm 1.6(211)$ & 0.505 \\
\hline \multirow[t]{2}{*}{ APOC3 } & $(\mathrm{mg} / \mathrm{dl})$ & + & $6.6 \pm 2.7(13)$ & $6.0 \pm 2.3(144)$ & 0.394 \\
\hline & & - & $10.7 \pm 3.9(6)$ & $9.1 \pm 3.0(211)$ & 0.210 \\
\hline \multirow[t]{2}{*}{ APOE } & $(\mathrm{mg} / \mathrm{dl})$ & + & $4.8 \pm 2.0(13)$ & $4.3 \pm 1.0(144)$ & 0.114 \\
\hline & & - & $4.7 \pm 1.7(6)$ & $4.7 \pm 1.2(211)$ & 0.979 \\
\hline
\end{tabular}

Values are presented as mean \pm standard deviation. The number of subjects available for the analysis is shown in parentheses. $P$-values were calculated using Student's t-test
Previously, Li and colleagues reported that an SNP in $L D L R$ exon 13 (rs5925) was associated with susceptibility to HCV infection [12], but we did not detect a significant difference in the SNP in our cohort. This difference may be due to the fact that the previous study involved a smaller subject cohort (a total of 156 subjects) as compared with our study (378 subjects). Zhu and associates reported that an SNP in the $A P O B$ promoter region (rs934197) was associated with susceptibility to HCV infection, and showed that $\mathrm{HCV}$-infected patients had significantly lower levels of LDL-C as compared with healthy individuals [25]. Although we did not analyze SNPs in the promoter region, a similar tendency of lower LDL-C levels was observed; HCV-positive subjects with AA genotype of $A P O B$ exhibited lower LDL-C levels than the other genotypes. Moreover, rs1042034 in $A P O B$ is known to regulate biding to the LDLR and is therefore assumed to cause a change in the binding affinity of APOB to LDLRs [26]. These findings are further supportive of a close relationship between the life cycle of $\mathrm{HCV}$ and host $A P O B$ polymorphism.

Since serum lipid levels are very important risk factors for cardiovascular disease, several large-scale screenings for SNPs concerning serum lipid-regulator genes have been reported. Regarding studies of the $A P O B$ SNP rs1042034, the genome-wide association study (GWAS), which included more than 100,000 individuals of European ancestry, reported that polymorphism of rs1042034 was significantly associated with decreased TG and increased HDL-C levels [27]. In a study involving several ethnic groups, rs1042034 was significantly associated with lower TC and LDL-C levels only in Hispanics [28]. As for Asians, rs1042034 was significantly associated with lower TG and higher HDL-C levels in South Asians, compatible with the European GWAS, but there was no significant association in East Asians [27]. Although the underlying mechanism of the changes in serum lipid levels caused by this SNP have still not been elucidated, it appears $A P O B-100$ mutations and polymorphisms may change the conformation of APOB-100, thereby leading to a change in LDL metabolism through the interaction of APOB-100 with the LDLR.

Based on the findings mentioned above, we can speculate that a relationship exists between $\mathrm{HCV}$ infection and lipid metabolism disorders through SNPs of APOB100 , whereby the AA genotype (minor allele homozygote) of rs1042034 could facilitate serum LDL uptake via LDLR on hepatocytes by modifying their mutual affinity and interaction, and consequently, the serum LDL-C level could be decreased. As a result, the susceptibility to $\mathrm{HCV}$ infection could be increased because $\mathrm{HCV}$ particles exist as LVPs and enter into the liver with LDL. However, it is not clear why genotype AA was associated with higher serum TG levels as compared with genotype 
non-AA, and further studies are needed to investigate this relationship in greater detail.

In the comparison of lipid levels by genotype, serum levels of LDL-C and TG showed significant differences between AA and non-AA genotype (Table 3), whereas these differences disappeared when comparing by $\mathrm{HCV}$ status (Table 4), indicating that HCV infection itself did not have much influence on lipid metabolism, which supports our hypothesis.

Interestingly, a large Japanese cohort study revealed that $\mathrm{HCV}$ infection causes not only lower $\mathrm{TC}$ and LDL-C levels but also significant lower serum HDL-C and TG levels [21] and they suggest that the HCV infection itself might directly cause hypolipidemia, irrespective of host factors including age, hepatic damage, and nutritional state. Furthermore, it has been reported that $\mathrm{HCV}$ genotype $3 \mathrm{a}$ and 4 are associated with hypocholesterolemia in western patients $[29,30]$. However, there was no association between $\mathrm{HCV}$ genotypes and lipid profile or SNP pattern in our cohort (data not shown). This may be partly explained by the fact that the most frequent genotype was $1 \mathrm{~b}(81 \%)$, which is the most common genotype in the Japanese population, while genotypes $3 \mathrm{a}$ and 4 are very rare.

Therefore, the possibility of a direct interaction of HCV with lipid metabolism could not be completely ruled out in our study and need to be confirmed in a more detailed investigation.

There are some potential limitations of our study. First, regarding the $\mathrm{HCV}$ negative cohort, we could not completely rule out the possibility of including individuals in whom $\mathrm{HCV}$ had been eradicated naturally because we enrolled subjects who were negative for serum anti-HCV antibody. Second, the lipid metabolism profiles could have been altered by differences in liver function, which can be affected by various hepatic disorders. However, in the present study, we carefully limited the participants to Child-Pugh A, and excluded subjects with NASH, HBV infection, or HCC, and therefore the baseline characteristics and liver function levels of the participants were well balanced between the two groups. Although our study had a limitation in terms of not covering all SNPs in lipid regulators, our results suggested the possibility that an $A P O B-100$ SNP, rs1042034, influences the susceptibility to $\mathrm{HCV}$ infection by their entry into the liver through the LDLR. Our data may have important implications for identifying individuals with higher susceptibility to $\mathrm{HCV}$ infection via SNP of lipid regulators. Exploring the molecular mechanism underlying these results could provide important information for controlling the process of HCV infection and limiting the expansion of $\mathrm{HCV}$ infection.

In addition, in the treatment of chronic $\mathrm{HCV}$ infection, the rate of sustained virological response (SVR) subsequent to the approval of direct-acting antiviral agents has been dramatically increasing and the change in serum lipid levels after SVR is gaining attention [31]. Therefore, focusing on the influence of SNPs concerning lipid metabolism in HCV patients should have important implications for antivirus therapy in the future.

\section{Conclusions}

In conclusion, this study demonstrated that an APOB SNP, rs1042034, is closely associated with $\mathrm{HCV}$ infection through lipid metabolism alteration. The minor allele AA genotype may facilitate serum LDL uptake into hepatocytes via LDLR by modifying their affinity and interaction and may have an influence on HCV infection by their entry into the liver through the LDLR. Further studies are needed to explore the mechanism underlying these results, which could provide important information for controlling the process of $\mathrm{HCV}$ infection.

\section{Abbreviations}

APOA1: Apolipoprotein A1; APOA2: Apolipoprotein A2; APOB: Apolipoprotein B; APOC2: Apolipoprotein C2; APOC3: Apolipoprotein C3; APOE: Apolipoprotein E; HCV: Hepatitis virus C; HDL-C: High density lipoprotein cholesterol; LDL-C: Low density lipoprotein cholesterol; TC: Total cholesterol; TG: Total triglycerides

\section{Acknowledgments \\ The authors wish to acknowledge Mitsuyasu Yano, Hiroshi Shibata, Toshihiro Omoya, Mari Urata, Kanako Otsuka (Tokushima Prefectural Central Hospital), Masako Sei (Tokushima Health Screening Center), Akemi Tsutsui, Hiroshi Fukuno, Fumiko Kishi (Tokushima Municipal Hospital), Masahiko Nakasono (Handa Hospital), Tatsuhiko Shiraishi (Tokushima Prefectural Miyoshi Hospital), Katsuyoshi Tamaki (Ohkubo Hospital), Yoshitaka Imoto, Sayo Takahashi and Tatsunao Sueuti, (Yoshinogawa Medical Center), who provided coordination in enrolling the subjects, and Yoshihiro Okayama (Clinical Trial Center for Developmental Therapeutics, Tokushima University Hospital) who provided advice to statistical analyses.}

\section{Funding}

None

\section{Availability of data and materials}

The date generated and analyzed during this study are available from the corresponding author on reasonable request.

\section{Authors' contributions}

Designed and coordinated the study: RH, MK, YS, TT and TT. Performed the statistical analyses: RH, MK and II. Collected the data and critically reviewed the manuscript: RH, MK, YS, TT, TT, T, HT, NM, HS, HH, II, MS, TO and TT. Wrote the manuscript: RH, MK, YS and TT. All authors approved the final version of the manuscript.

\section{Ethics approval and consent to participate}

The study protocol was conducted according to the guidelines contained within the Declaration of Helsinki and was approved by the institutional review board of Tokushima University Hospital (Approval number $\mathrm{H}-26$ ). Written informed consent was obtained from all participants before entry into the study.

Consent for publication

Not applicable.

Competing interests

The authors declare that they have no competing interests. 


\section{Publisher's Note}

Springer Nature remains neutral with regard to jurisdictional claims in published maps and institutional affiliations.

\section{Author details}

'Department of Gastroenterology and Oncology, Tokushima University Graduate School of Biomedical Sciences, 3-18-15, Kuramoto-cho, Tokushima 770-8503, Japan. ${ }^{2}$ Department of Gastroenterology, Yoshinogawa Medical Center, Yoshinogawa, Tokushima 776-8511, Japan. ${ }^{3}$ Department of Internal Medicine, Tokushima Health Screening Center, 1-10-3, Kuramoto-cho, Tokushima 770-0042, Japan. ${ }^{4}$ Department of Human Genetics, Tokushima University Graduate School of Biomedical Sciences, 3-18-15, Kuramoto-cho, Tokushima 770-8503, Japan. ${ }^{5}$ Department of General Medicine and Community Health Science, Tokushima University Graduate School of Biomedical Sciences, 3-18-15, Kuramoto-cho, Tokushima 770-8503, Japan.

\section{Received: 24 November 2017 Accepted: 18 January 2018}

\section{Published online: 30 January 2018}

\section{References}

1. Mohd Hanafiah K, Groeger J, Flaxman AD, Wiersma ST. Global epidemiology of hepatitis C virus infection: new estimates of age-specific antibody to HCV seroprevalence. Hepatology. 2013;57(4):1333-42.

2. Webster DP, Klenerman P, Dusheiko GM. Hepatitis C. Lancet. 2015:385:1124-35.

3. Zeisel MB, Fofana I, Fafi-Kremer S, Baumert TF. Hepatitis C virus entry into hepatocytes: molecular mechanisms and targets for antiviral therapies. J Hepatol. 2011;54(3):566-76.

4. Kim DS, Burt AA, Ranchalis JE, Jarvik ER, Rosenthal EA, Hatsukami TS, et al. Novel gene-by-environment interactions: APOB and NPC1L1 variants affect the relationship between dietary and total plasma cholesterol. J Lipid Res. 2013;54(5):1512-20.

5. Powell LM, Wallis SC, Pease RJ, Edwards YH, Knott TJ, Scott J. A novel form of tissue-specific RNA processing produces apolipoprotein-B48 in intestine. Cell. 1987;50(6):831-40.

6. Aizawa Y, Seki N, Nagano T, Abe H. Chronic hepatitis C virus infection and lipoprotein metabolism. World J Gastroenterol. 2015;21(36):10299-313.

7. Fukuhara T, Ono C, Puig-Basagoiti F, Matsuura Y. Role of lipoproteins and apolipoproteins in particle formation of hepatitis $C$ virus. Trends Microbiol. 2015;23(10):618-29.

8. Agnello V, Abel G, Elfahal M, Knight GB, Zhang QX. Hepatitis C virus and other Flaviviridae viruses enter cells via low density lipoprotein receptor. Proc Natl Acad Sci U S A. 1999;96(22):12766-71.

9. Benn M. Apolipoprotein B levels, APOB alleles, and risk of ischemic cardiovascular disease in the general population, a review. Atherosclerosis. 2009;206(1):17-30.

10. Cerda A, Genvigir FD, Arazi SS, Hirata MH, Dorea EL, Bernik MM, et al. Influence of SCARB1 polymorphisms on serum lipids of hypercholesterolemic individuals treated with atorvastatin. Clin Chim Acta. 2010;411(9-10):631-7.

11. Yang KC, Su YN, Shew JY, Yang KY, Tseng WK, Wu CC, et al. LDLR and ApoB are major genetic causes of autosomal dominant hypercholesterolemia in a Taiwanese population. J Formos Med Assoc. 2007;106(10):799-807.

12. Li H, Liu Z, Han Q, Li Y, Chen J. Association of genetic polymorphism of low-density lipoprotein receptor with chronic viral hepatitis $C$ infection in Han Chinese. J Med Virol. 2006:78(10):1289-95.

13. Hennig BJ, Hellier S, Frodsham AJ, Zhang L, Klenerman P, Knapp S, et al. Association of low-density lipoprotein receptor polymorphisms and outcome of hepatitis C infection. Genes Immun. 2002;3(6):359-67.

14. Caruz A, Neukam K, Rivero-Juárez A, Herrero R, Real LM, Camacho A, et al. Association of low-density lipoprotein receptor genotypes with hepatitis $C$ viral load. Genes Immun. 2014;15(1):16-24.

15. Price DA, Bassendine MF, Norris SM, Golding C, Toms GL, Schmid ML, et al. Apolipoprotein epsilon3 allele is associated with persistent hepatitis $C$ virus infection. Gut. 2006;55(5):715-8.

16. Wozniak MA, Itzhaki RF, Faragher EB, James MW, Ryder SD, Irving WL. Apolipoprotein E-epsilon 4 protects against severe liver disease caused by hepatitis C virus. Hepatology. 2002;36(2):456-63.

17. Delgado-Lista J, Perez-Jimenez F, Ruano J, Perez-Martinez P, Fuentes F, Criado-Garcia J, et al. Effects of variations in the APOA1/C3/A4/A5 gene cluster on different parameters of postprandial lipid metabolism in healthy young men. J Lipid Res. 2010;51(1):63-73.
18. Kuhlmann I, Minihane AM, Huebbe P, Nebel A, Rimbach G. Apolipoprotein E genotype and hepatitis C, HIV and herpes simplex disease risk: a literature review. Lipids Health Dis. 2010;9:8.

19. Itoh Y, Mizuki N, Shimada T, Azuma F, Itakura M, Kashiwase K, et al. Highthroughput DNA typing of HLA-A, -B, -C, and -DRB1 loci by a PCR-SSOP-Luminex method in the Japanese population. Immunogenetics. 2005;57(10):717-29.

20. Butt AA, Xiaoqiang W, Budoff M, Leaf D, Kuller LH, Justice AC. Hepatitis C virus infection and the risk of coronary disease. Clin Infect Dis. 2009;49(2):225-32.

21. Miyazaki T, Honda A, Ikegami T, Saitoh Y, Hirayama T, Hara T, et al. Hepatitis $C$ virus infection causes hypolipidemia regardless of hepatic damage or nutritional state: an epidemiological survey of a large Japanese cohort. Hepatol Res. 2011;41(6):530-41

22. Gastaminza P, Cheng G, Wieland S, Zhong J, Liao W, Chisari FV. Cellular determinants of hepatitis $C$ virus assembly, maturation, degradation, and secretion. J Virol. 2008:82(5):2120-9.

23. André $P$, Komurian-Pradel F, Deforges $S$, Perret $M$, Berland $J$, Sodoyer $M$, et al. Characterization of low- and very-low-density hepatitis C virus RNAcontaining particles. J Virol. 2002;76(14):6919-28.

24. Huang H, Sun F, Owen DM, Li W, Chen Y, Gale M, et al. Hepatitis C virus production by human hepatocytes dependent on assembly and secretion of very low-density lipoproteins. Proc Natl Acad Sci U S A. 2007;104(14):5848-53.

25. Zhu C, Zhang R, Liu D, Mukhtar MM, Liu W, Peng G, et al. Association of functional polymorphism of ApoB promoter with hepatitis $C$ virus infection. Clin Chim Acta. 2009:401(1-2):124-7.

26. Boren J, Lee I, Zhu W, Arnold K, Taylor S, Innerarity TL. Identification of the low density lipoprotein receptor-binding site in apolipoprotein B100 and the modulation of its binding activity by the carboxyl terminus in familial defective apo-B100. J Clin Invest. 1998;101(5):1084-93.

27. Teslovich TM, Musunuru K, Smith AV, Edmondson AC, Stylianou IM, Kosek $M$, et al. Biological, clinical and population relevance of 95 loci for blood lipids. Nature. 2010;466(7303):707-13.

28. Bryant EK, Dressen AS, Bunker CH, Hokanson JE, Hamman RF, Kamboh MI, et al. A multiple replication study of plasma lipoprotein levels-associated SNPs identified in recent GWAS. PLoS One. 2013;8(5):e63469.

29. Hofer H, Bankl HC, Wrba F, Steindl-Munda P, Peck-Radosavljevic M, Osterreicher C, et al. Hepatocellular fat accumulation and low serum cholesterol in patients infected with HCV-3a. Am J Gastroenterol. 2002:97(11):2880-5.

30. Marzouk D, Sass J, Bakr I, El Hosseiny M, Abdel-Hamid M, Rekacewicz C, et al. Metabolic and cardiovascular risk profiles and hepatitis $C$ virus infection in rural Egypt. Gut. 2007;56(8):1105-10.

31. Meissner EG, Lee YJ, Osinusi A, Sims Z, Qin J, Sturdevant D, et al. Effect of sofosbuvir and ribavirin treatment on peripheral and hepatic lipid metabolism in chronic hepatitis C virus, genotype 1-infected patients. Hepatology. 2015:61(3):790-801.

\section{Submit your next manuscript to BioMed Central and we will help you at every step:}

- We accept pre-submission inquiries

- Our selector tool helps you to find the most relevant journal

- We provide round the clock customer support

- Convenient online submission

- Thorough peer review

- Inclusion in PubMed and all major indexing services

- Maximum visibility for your research

Submit your manuscript at www.biomedcentral.com/submit
) Biomed Central 